\title{
Genital prolapse at university hospital of Cocody: clinical aspects and therapeutic management
}

\author{
Charles Kakou*, Roland Adjoby, Raoul Kasse, Victorine Assuikwe, \\ Boston Mian, Serge Boni
}

Department of Obstetrics and Gynecology, University Felix Houphouet Boigny, Abidjan, Côte d'Ivoire

Received: 11 February 2018

Accepted: 27 March 2018

\section{*Correspondence:}

Dr. Charles kakou,

E-mail: kakoucharles@yahoo.fr

Copyright: ( ) the author(s), publisher and licensee Medip Academy. This is an open-access article distributed under the terms of the Creative Commons Attribution Non-Commercial License, which permits unrestricted non-commercial use, distribution, and reproduction in any medium, provided the original work is properly cited.

\section{ABSTRACT}

Background: To determine the epidemiological aspects of genital prolapse; to describe the different clinical aspects of genital prolapse observed and to evaluate the therapeutic management of genital prolapse at the University hospital of Cocody (UH-C).

Methods: We did an observational and transversal study with a descriptive purpose over 5 years from 2012 to 2016 in the Gynecology and obstetrics department of UH-C. The studied population was all cases of genital prolapse diagnosed and treated in the service during the period of the study. A follow-up over one year after surgery has been observed to evaluate surgical outcomes and recurrences. Genital prolapse was generally a uterine prolapse at stage 3 or 4. It was associated to cystocele in $31.4 \%$. We did not find stress urinary incontinence associated with prolapse in our study. The surgical intervention performed was, in the majority case, the triple perineal intervention with success of $95.6 \%$. A case of recurrence in the form of cystocele has been observed to a year of decline.

Results: Genital prolapse was relatively common. It accounted for $0.5 \%$ of all gynecological visits. Women were young with an average age of 39.5 years. $62.9 \%$ were multiparous. $62.5 \%$ had given birth at least once at home without medical assistance. The reason for consultation the most watched was the projection of body at the vulva.

Conclusions: Genital prolapse is a condition under estimated in Côte d'Ivoire. It represented $0.5 \%$ of the gynecological visits. Obstetric traumas were frequently found in our young patients with genital prolapse. The sociocultural considerations have contributed to delay consultations, to observe very advanced stages. The surgery performed was mainly the perineal triple surgery.

Keywords: Genital prolapse, Hysterectomy, Triple perineal surgery

\section{INTRODUCTION}

Genital prolapse is a functional pathology. Genital prolapse is the consequence of the alteration of both muscle and fibro-ligament support and suspension of the pelvic viscera systems. ${ }^{1}$ Advanced technologies of exploration exist for a specific diagnosis. But the diagnosis is largely facilitated by clinical examination. The problem posed in the case of this pathology is essentially surgical therapeutic support. Indeed, there are many surgical techniques. The choice of surgical technique can be difficult for several reasons including the operative indication of application of the technique, the mastering of the technique and the availability of technology.

In our African context, patients consult already advanced stages affecting their quality of life and imposing 
particular surgical techniques. We have available vaginal repair techniques in our work environment. ${ }^{2}$

Therefore, we felt that it was appropriate to conduct this study whose objective was to clarify the epidemiological aspects, to describe the clinical characteristics and to evaluate the results of surgical management of our cases of genital prolapse.

\section{METHODS}

We did this observational and transversal study over 5 years from 2012 to 2016 in the Gynecology and obstetrics department of the University Hospital of Cocody. Patients were identified at the consultation scheduled or not from our service.

We were stadified the genital prolapse according to the classification of Baden and Walker. Ano-rectal and urinary functional signs have been identified. Patients with a functional gene or a failure of the physical treatment of rehabilitation perineal were scheduled for surgery after a review of operability. When this situation is satisfactory, we have then proceeded to prolapse surgery.

Surgical treatment was performed vaginally in all cases of prolapse. After surgical treatment, post-operative follow-up of one year has been observed to evaluate surgical outcomes (or recidivism) and functional outcomes. Limitations to our study were a lack of realization of a routine pelvic MRI to establish classification POP-Q/ICS of prolapse.

\section{RESULTS}

\section{Frequency}

During the study's period, we recorded 57 cases of genital prolapse in consultation on 10795 consultations. So, the frequency was $0.5 \%$. Among these 57 patients, 22 did not come back after the first consultation.

About 35 treated patients, 26 received a surgical treatment (74.3\%). That represented $4.6 \%$ of 566 gynecological interventions scheduled, carried out during the study's period.

\section{Characteristics of patients and clinical data}

The age of the patients is indicated in Table 1. The average was 39.5 years. Medical histories were as follows: patients had no factor of intra-abdominal hypertension in $91.4 \%$; chronic constipation was found in $8.6 \%$. There is no surgical history in $85.7 \% .54 .3 \%$ of the patients were not menopausal. The clinical examination data are indicated in Table 2.
Table 1: Epidemiological data.

\begin{tabular}{|lll|}
\hline Characteristics & \multicolumn{2}{c}{$\%$} \\
\hline Age (years): average $=39.5$; extremes of 18 and 70 \\
\hline$\leq 29$ & 6 & 17.1 \\
\hline $30-39$ & 6 & 17.1 \\
\hline $40-49$ & 10 & 28.6 \\
\hline $50-59$ & 7 & 20 \\
\hline$\geq 60$ & 6 & 17.2 \\
\hline Parity & & \\
\hline Nulliparous $(0)$ & 3 & 8.6 \\
\hline Primiparous $(1)$ & 4 & 11.4 \\
\hline Pauciparous $(2-3)$ & 6 & 17.1 \\
\hline Multiparous $(4-5)$ & 10 & 28.6 \\
\hline Grande multiparous $(>5)$ & 12 & 34.3 \\
\hline Factor of intra-abdominal hypertension & & \\
\hline None & 32 & 91.4 \\
\hline Constipation & 3 & 8.6 \\
\hline Obesity present & 0 & 0 \\
\hline Menopause $\left(p=3,841 ; \mathrm{x}^{2}=25,96\right)$ & & \\
\hline Yes & 16 & 45.7 \\
\hline No & 19 & 54.3 \\
\hline Total & 35 & 100 \\
\hline
\end{tabular}

Table 2: Clinical data.

\begin{tabular}{|c|c|c|c|}
\hline \multicolumn{2}{|c|}{ Clinical examination data } & $\mathbf{N}$ & $\%$ \\
\hline \multirow{2}{*}{ Symptom } & $\begin{array}{l}\text { Sensation of mass } \\
\text { intra vaginal }\end{array}$ & 5 & 14.3 \\
\hline & $\begin{array}{l}\text { Projecting from body } \\
\text { in vulva }\end{array}$ & 30 & 85.7 \\
\hline Urinary symptom & Pollakiuria & 5 & 14.3 \\
\hline \multirow[t]{5}{*}{$\begin{array}{l}\text { Ano-rectal } \\
\text { symptom }\end{array}$} & dyschesia & 3 & 8.6 \\
\hline & $\begin{array}{l}\text { Abdominal and } \\
\text { pelvic pain }\end{array}$ & 4 & 11.4 \\
\hline & Uterine prolapse & 15 & 42.9 \\
\hline & Cystocele & 5 & 14.3 \\
\hline & $\begin{array}{l}\text { Cystocele and uterine } \\
\text { prolapse }\end{array}$ & 7 & 20 \\
\hline \multirow[t]{2}{*}{ Type of prolapse } & $\begin{array}{l}\text { Rectocele and uterine } \\
\text { prolapse }\end{array}$ & 4 & 11.4 \\
\hline & $\begin{array}{l}\text { Complete genital } \\
\text { prolapse }\end{array}$ & 4 & 11.4 \\
\hline \multirow{5}{*}{$\begin{array}{l}\text { Stages of Baden } \\
\text { and Walker }\end{array}$} & 1 & 2 & 5.7 \\
\hline & 2 & 3 & 8.6 \\
\hline & 3 & 8 & 22.9 \\
\hline & 4 & 22 & 62.8 \\
\hline & Total & 35 & 100 \\
\hline
\end{tabular}

\section{Therapeutic support}

The majority of our patients received surgery to $74.3 \%$ of cases. The triple perineal intervention was the most performed surgical intervention with $61.6 \%$ (see Table $3)$. The triple perineal intervention took place without incident in $80.8 \%$ of cases (Figure $\mathrm{A}$ and $\mathrm{B}$ ). We recorded two bladder injuiries and one hemorrhagic 
complication. The postoperative times were simple in $76.9 \%$ of cases.

Table 3: Data of therapeutic support.

\begin{tabular}{|lll|}
\hline Type of intervention & N & $\%$ \\
\hline Surgery of cystocele & 5 & 19.2 \\
\hline Triple perineal intervention & 16 & 61.6 \\
\hline $\begin{array}{l}\text { Triple perineal intervention + Richter } \\
\text { spinofixation }\end{array}$ & 5 & 19.2 \\
\hline Total & 26 & 100 \\
\hline
\end{tabular}

These complications observed needed three days in addition during hospitalization. They were not specific to the treatment of genital prolapse. Patients were reviewed one year after the treatment of genital prolapse for assessment of treatment. On the 26 operated, three (03) were not present for the post-operative control. Healing has occurred in $95.6 \%$ of cases and there was a case of recidivism.

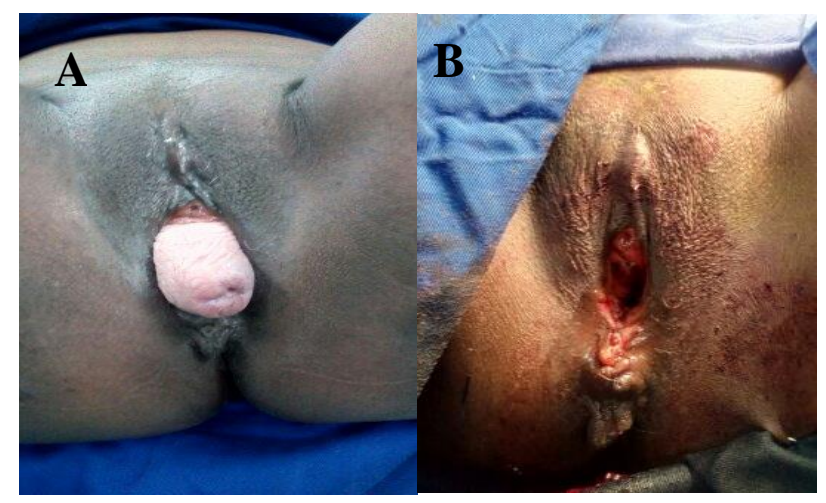

Figure A: Genital prolapse before surgery, B: Result after surgery (triple perineal intervention).

\section{DISCUSSION}

We reported 57 cases of genital prolapse; which represented $0.5 \%$ of the gynecological consultations. The annual average was 11.4 cases. We had 35 cases of genital prolapse that were treated during the study period or an annual average of 7 cases. Other cases of genital prolapse didn't come back to get treatment. This pathology represented $4.5 \%$ of interventions in gynecology at the UH-C (on 10795). In Africa, women did not consult the physician, did not go to hospital. Poverty and ignorance were in favor for this situation. Published studies reveal 5 to 6 consultations per year for genital prolapse in sub-Saharan Africa and 10-32 consultations per year in North Africa. ${ }^{3-5}$ In Western and North American countries, it is also a frequent pathology. 6

In European Countries, genital prolapse is responsible for $13 \%$ of all hysterectomies. ${ }^{7}$ Genital prolapse is the leading cause of hysterectomy in Quebec. The frequency of genital prolapse in the black women group appears low; under estimated. This could be explained by the non-consultation for the following reasons: the handicap that would represent the genital prolapse in african women and sociocultural considerations of this condition. Moreover, a protective factor against the occurrence of genital prolapse is the natural arch of the basin of african woman. ${ }^{8}$ Concerning the age of patients, the average was 39.5 years. In african literature the average age was between 38 and 46 years. ${ }^{3}$ The average age is young compared to the age in the occidental literature, 65.1 years. ${ }^{6}$

Regarding history, pelvic surgery was found in only $14.3 \%$ of patients. The factor of intra-abdominal hypertension as chronic constipation was found in $8.6 \%$. This was not significant ( $\mathrm{p}=3,841) .54 .3 \%$ of the patients were in the childbearing age. A predominance of this category of women can be found in the regional literature. ${ }^{3}$ In the European countries, in France for example, more than $90 \%$ of patients were menopausal. ${ }^{6}$ Patients were multiparous and large multiparous in $62.9 \%$. It's according with the role of obstetrical trauma; like in the majority cases of african literature. ${ }^{3}$ For Ringold, the risk of genital prolapse increases significantly with the number of vaginal delivery. In addition, in our study, in the obstetric history, $62.5 \%$ of patients had given birth at least once at home without medical assistance. ${ }^{9}$

Symptom was a mass felt out of the vulva. Genital prolapse at stage 3 or 4 was founded at clinical examination in $85.7 \%$ of cases according to the classification of Baden and Walker [10]. Our patients were not classified according to the ICS/POP-Q classification because only $14.3 \%$ were in the earlier stage ( 1 or 2 ) of Baden and Walker's classification. In addition; these two classifications are enough near. And, we have no pelvic MRI for a better investigation.

Through ignorance or modesty women hiding their pathology and do consult only in advanced stages. Advanced forms were almost all of the lesions observed. ${ }^{4}$ While in Europa the women consult at an early stage. ${ }^{6}$ Mono-segmentary genital prolapse of young women objected to the menopausal woman who touches all the different pelvic floors in varying proportions. We noted 5 cases pollakiuria $(14.3 \%)$ in relation to a bladder infection treated by antibiotic in line with cytobacteriological examination of urinalysis results. Moreover, we did not observed cases of stress urinary incontinence; it was probably related to our studied population. In the literature, stress urinary incontinence was associated to genital prolapse in 6 to $43 \%$. $^{1,4-6}$ No patient in our study had an urodynamic assessment; they did not provide indications. In the literature, urodynanmic investigation must not be systematic. ${ }^{11}$ The support is a difficult challenge. The treatment was essentially surgical in $74.3 \%$. Vaginal route was used in $100 \%$. In the literature, the vaginal route is the appropriate approach for the genital prolapse treatment. ${ }^{9,12,13}$ There are a multitude of operational techniques for surgical 
correction, ranging from the simple hysterectomy to complex surgery using prosthetic material not absorbable. The treatment must meet several objectives: the repositioning of the various bodies and according to their anatomical relationships, obtaining a good anatomical result and the possibility of having a satisfactory physical and sexual activity. We realized only interventions without prosthetics, which is available in our work environment. The triple perineal intervention was made in $61 \%$ of the patients. Per operative complications were two (2) bladder injuries recognized and immediately processed with favorable result. A hemorrhagic complication was observed. These complications are touring complications in surgery of genital prolapse. There had no other complications in post-operative time.

The postoperative hospitalization was 4 days on average and ranged from 3 to 7 days. The two patients with bladder injuries have stayed seven (7) days for better post-operative monitoring. Our patients have been revised to 6 weeks post-operative then at 3 months and 6 months post-surgery. These consultations revealed no complications in the medium term. Functionally, no anomalies were reported.

In literature, we found dyspareunia of intromission postoperative most often in connection with a vaginal dryness or an excessive vaginectomy or a tight myorraphy of the bullpen of the anus. ${ }^{4,13,14}$ Success rate was $95.6 \%$. Twelve months post-operative later, one case of recidivism as a bladder prolapsed was noted. Expert teams such as Dargent noted success in $83 \%$. Our low proportion of recidivism would be due to the experience of the operators. ${ }^{14}$

\section{CONCLUSION}

Genital prolapse is a pathology under estimated in Côte d'Ivoire. It represented $0.5 \%$ of the gynecological consultations over the study period. This disease occurs often in young african women in childbearing age unlike the developed countries. Obstetric trauma was the major factor of risk in these young women.

Clinical aspects were dominated by the prolapse in advanced forms. The triple perineal intervention was performed vaginally with success result to $95.6 \%$ rate. Despite this favorable therapeutic approach, the preventive attitude should be rigorous.

Funding: No funding sources Conflict of interest: None declared
Ethical approval: The study was approved by the Institutional Ethics Committee

\section{REFERENCES}

1. Deval B, Blanc B. Genital and urinary prolapse: clinical examination. Reality Gynecol Obstet. 2006;108:1-6.

2. R de Tayrac. Symptoms and quality of life in the genital prolapse. Pelvic Perineol. 2009,4(2):121.

3. Dia A, Touré CT, Diop MB, Thognon PH, Diop A. Genital prolapse in Dakar. Dakar Méd. 1991;36 (1):39-46.

4. Ben Hmid R, Mahjoub S, Seltana N, Lebbi I, Zouari F. Urogenital prolapse: epidemiological aspects, functional outcomes and complications about 64 cases. Maghreb Médical 2002;22:43-5.

5. Chelli D, Chennoufi MB, Ben Temime R, Balsac A, Mathlouri N, Souki A et all. Place of the Ritcher spinofixation in the treatment of genital prolapse about 63 cases. Maghreb Médical. 2002;22:281-4.

6. Adjoussou SA, Bohoussou E, Bastide S, Letouzey V, Fatton B, R. de Tayrac. Prevalence of functional disorders and anatomical-functional associations for women with genital prolapse. Progress in Urol 2014;24:511-7.

7. Blanc B, Deval B. Prolapsus génital: Nosological context and common pathogenesis. Pelvic Perineol.2005:175-86.

8. Barrat J, Pigne A, Marpeau L. Genital prolapse and its treatment. Paris: Masson ;1988: 128-30.

9. Ringold S, Cassio L, Glass RM Uterine prolapsed. JAMA. 2005;293(16):2054.

10. Le Normand. Management of genital prolapse. Progress in Urol. 2014;24:925-8

11. Donon L, Warembourg S, Lapray JF, Cortesse A, Hermieue JF, Fatton B, et al. Balance sheet prior to the surgical treatment of genital prolapse: recommendations for clinical practice. Progress in Urol. 2016;26(1):S8-26.

12. Raudrant D. anterior colpocele. Pelvi-périnéologie. 2005:187-94.

13. Rosenthal C. Uterine prolapse. Pelvic Perineol. 2005: 195-202.

14. Dargent D, Mathevet P, Mellier G. Vaginal surgical treatment of the genital prolapse. Encycl Med Chir. 2000:41-80.

Cite this article as: Kakou C, Adjoby R, Kasse R, Assuikwe V, Mian B, Boni S. Genital prolapse at university hospital of cocody: clinical aspects and therapeutic management. Int J Reprod Contracept Obstet Gynecol 2018;7:1673-6. 